\title{
STRATEGI PENGEMBANGAN POTENSI WISATA LIMA PANTAI DI KECAMATAN SAPTOSARI KABUPATEN GUNUNG KIDUL
}

\author{
Imam Arifa'illah Syaiful Huda', M. Farouq Ghazali Matondang²
}

IUIN Sultan Thaha Saifuddin

Jl. Lintas Jambi - Muara Bulian KM.16, Simpang Sei Duren, Jambi Luar Kota, Muaro Jambi, Jambi

2Universitas Negeri Medan

J. William Iskandar Ps. V, Kenangan Baru, Kec. Percut Sei Tuan, Kabupaten Deli Serdang, Sumatera Utara

Email corresponding: farouqmatondang@unimed.ac.id

\begin{tabular}{|c|c|c|}
\hline Dikirimkan: & Diterima: & Diterbitkan: \\
03-03-2020 & $20-06-2020$ & $27-07-2020$ \\
\hline
\end{tabular}

\begin{abstract}
The tourism sector has a positive influence on the economic growth of surrounding communities because the tourism sector can drive other sectors, such as the economic, social, and cultural sectors. Saptoari Subdistrict Gunung Kidul Regency has a large beach tourism potential for further development. Some beach tourism found in Saptosari Subdistrict are Nguyahan Beach, Ngobaran, Ngrenehan, Ngedan, and Butuh. According to data from the Department of Tourism, the number of tourists visiting Saptosari District has increased significantly. However, the beach tourism still has some problems and potential that have not yet been developed so that it inhibits the growth of tourism in the Saptosari District. This study aims to identify the characteristics of beaches in Saptosari Subdistrict, analyze potential and problems and develop tourism development strategies. This research is in the form of descriptive analytic with survey method and literature study. Data collection techniques through interviews, observation and documentation. While the analysis technique in research uses SWOT analysis. The results showed that the priority strategies that need to be carried out on 5 beaches are 1) developing tourist vehicles of all ages, 2) Organizing interesting events routinely (a calendar of regional/ national/ international events) by establishing cooperation with tourism management groups, 3) building telecommunications network, 4) The opening pringjono tourism area to expand tourist destinations in Nguyahan, 5) increasing product diversification typical for tourist souvenirs, 6) forming cleaning staff to create clean beaches, 7) developing culinary tourism (sea fish) and developing products interesting fish preparations, 8) design Ngeden Beach as a mainstay tour for special interests such as camping and tracking, 9) provide camping rental equipment and form a solid tourism management group to develop tourism, 10) provide special vehicle parking lots to look neat
\end{abstract}

Keywords: SWOT, Development, Beach Tourism

\begin{abstract}
Abstrak
Sektor pariwisata memiliki pengaruh yang positif terhadap pertumbuhan ekonomi masyarakat sekitar karena sektor pariwisata mampu menggerakkan sektor-sektor lainnya, seperti sektor ekonomi, sosial, dan budaya. Kecamatan Saptoari Kabupaten Gunung Kidul memiliki potensi wisata pantai yang besar untuk dikembangkan lebih lanjut. Beberapa wisata pantai yang terdapat di Kecamatan Saptosari yaitu Pantai Nguyahan, Ngobaran, Ngrenehan, Ngedan, dan Butuh. Menurut data Dinas Pariwisata jumlah wisatawan yang datang ke Kecamatan Saptosari mengalami peningkatan secara signifikan. Namun, wisata pantai tersebut masih memiliki beberapa masalah dan potensi yang belum dikembangkan sehingga menghambat pertumbuhan pariwisata di Kecamatan Saptosari. Penelitian ini bertujuan untuk mengidentifikasi karakteristik pantai di Kecamatan Saptosari, menganalisis potensi dan masalah serta menyusun strategi pengembangan pariwisata. Penelitian ini berupa deskriptif analitik dengan metode survei dan studi literatur. Teknik pengumpulan data melalui wawancara, observasi dan dokumentasi. Sedangkan teknik analisis dalam penelitian menggunakan analisis SWOT. Hasil penelitian menunjukan bahwa strategi prioritas yang perlu dilakukan pada 5 pantai yaitu 1) mengembangkan wahana wisata dari segala umur, 2) Mengadakan event yang menarik secara rutin (kalender event regional/nasional/international) dengan menjalin kerjasama dengan kelompok pengelola pariwisata, 3) membangun jaringan telekomunikasi, 4) membuka kawasan wisata pringjono untuk memperluas destinasi wisata di Nguyahan, 5) meningkatkan diversifikasi produk yang khas untuk cinderamata wisatawan, 6) membentuk petugas kebersihan agar tercipata pantai yang bersih, 7) mengembangan wisata kuliner (lkan laut) dan mengembangkan produk olahan ikan yang menarik, 8) mendesain Pantai Ngeden sebagai wisata andalan untuk minat khusus seperti camping dan tracking, 9) Menyediakan alat penyewaan camping dan membentuk kelompok pengelola pariwisata yang solid untuk mengembangkan pariwisata, 10) menyediakan lahan parkir kendaraan khusus agar terlihat rapi
\end{abstract}

Kata Kunci: SWOT, Pengembangan, Wisata Pantai 


\section{PENDAHULUAN}

Sektor pariwisata memiliki pengaruh yang positif terhadap pertumbuhan ekonomi masyarakat sekitar karena sektor pariwisata mampu menggerakkan sektor-sektor lainnya, seperti sektor ekonomi, sosial, dan budaya. Pariwisata merupakan bagian dari budaya suatu masyarakat, yaitu berkaitan dengan cara penggunaan waktu senggang yang dimilikinya. Pariwisata dapat disoroti dari bermacam sudut pandang karena memiliki sifat kompleks. Kompleksitas yang terkandung dalam pariwisata antara lain pariwisata sebagai pengalaman manusia, pariwisata sebagai perilaku sosial, pariwisata sebagai fenomena geografis, pariwisata sebagai sumber daya, pariwisata sebagai bisnis, dan parwisata sebagai industry (Smith, 1989 dalam Wardiyanta 2006).

Sektor pariwisata diharapkan menjadi katalisator dalam pembangunan (agent of development) dan dapat menunjang pembangunan berkelanjutan (sustainable development) karena mempunyai prospek yang menjanjikan. Lebih spesifik, sektor pariwisata diharapkan mampu menggerakkan ekonomi masyarakat. Harapan ini dikembangkan dalam suatu strategi pemberdayaan masyarakat melalui pengembangan pariwisara yang berbasis masyarakat atau community-based tourism development. Pengembangan pariwisata tidak lepas dari unsur fisik maupun non fisik (sosial, budaya, dan ekonomi), maka dari itu perlu diperhatikan peranan unsur tersebut. Faktor geografi merupakan faktor yang penting untuk pertimbangan perkembangan pariwisata. Perbedaan iklim merupakan salah satu faktor yang mampu menumbuhkan serta menimbulkan variasi lingkungan alam dan budaya, sehingga dalam mengembangkan kepariwisataan karakteristik fisik dan non fisik suatu wilayah (Sujali, 1989).

Kabupaten Gunungkidul memiliki potensi wisata yang cukup potensial dan beragam, mulai dari kekayaan alam pantai, gua, bukit dan pegunungan maupun potensi seni budaya dan peninggalan sejarah yang beragam dan tersebar di hampir 18 kecamatan. Potensi ini sangat berarti sejalan keberadaan Kabupaten Gunungkidul sebagai bagian dari Daerah Istimewa Yogyakarta yang merupakan daerah tujuan wisata kedua di Indonesia setelah Propinsi Bali.

Kecamatan Saptosari Kabupaten Gunung Kidul memiliki beberapa obyek wisata pantai yang mulai berkembang. Obyek wisata pantai ini perlu dikembangkan lebih lanjut untuk meningkatkan kesejahtraan masyarakat sekitar.
Untuk itu, perlu dilakukan inventarisasi dan analisis potensi wisata pantai sebagai dasar langkah awal dalam pengembangan wisata pantai di Kecamatan Saptosari Kabupaten Gunung Kidul. Beberapa objek wisata pantai yang masih perlu dikembangkan lebih lanjut yaitu Pantai Nguyahan, Ngobaran, Ngrenehan, Ngedan, dan Butuh. Dalam survey awal, beberapa masalah yang terdapat di 5 pantai tersebut yaitu ketersedian infrastruktur yang kurang di pantai Butuh dan Ngedan, sampah yang masih berserakan di pantai Ngrenehan serta tata kelola tempat penjualan ikan yang masih semrawut, dan pengelolaan lahan parkir yang kurang baik di pantai Ngobaran dan Nguyahan.

Berdasarkan kondisi di atas, perlu dilakukan penelitian untuk merumuskan strategi alternatif pengembangan wisata 5 pantai di Kecamatan Saptosari Kabupaten Gunung Kidul. Perumusan strategi pengembangn obyek wisata pantai ini berdasarkan identifikasi faktor eksternal dan internal yang berpengaruh terhadap obyek wisata serta diharapkan mengetahui peluang dan kekuatan yang dimiliki untuk menentukan rencana serta mengatasi kelemahan dan ancaman dengan rencana perbaikan.

\section{METODOLOGI PENELITIAN}

Penelitian ini bersifat deskriptif kualitatif dengan melakukan pengamatan langsung atau observasi, wawancara dan dokumentasi. Tujuan utama dari penggunaan metode ini adalah untuk menggambarkan sifat suatu keadaan yang sementara berjalan pada saat tertentu di wilayah penelitian, dan memeriksa sebab-sebab dari suatu gejala tertentu (Travers, 1978 dalam Sevilla et al., 1993). Penelitian ini dilakukan di 5 pantai di Kecamatan Saptosari Kabupaten Gunung Kidul, yaitu Pantai Nguyahan, Ngobaran, Ngrenehan, Ngedan, dan Butuh.

Data yang digunakan dalam penelitian ini terdiri dari data primer dan data sekunder. Teknik yang dapat digunakan peneliti dalam pengumpulan data primer yaitu observasi dan wawancara. Data sekunder dapat diperoleh dari berbagai sumber seperti Badan Pusat Statistik (BPS), buku, laporan, jurnal, dan lainlain. Penulis melakukan wawancara kepada pengurus/kelompok pariwisata, pengurus desa, pengunjung, serta pedagang. Sedangkan teknik studi literatur dilakukan dengan cara mengumpulkan dan menganalisis berbagai referensi seperti artikel ilmiah, jurnal, buku, dan arsip akademis yang menjelaskan temuan, ide atau pendapat, dan konsep atau teori 
yang berhubungan dengan pengembangan pariwisata.

Metode analisis yang digunakan yakni analisis SWOT. Analisis SWOT yang merupakan analisis kualitatif yang dilaksanakan dengan mengkaji faktor-faktor internal dan eksternal. Faktor internal dalam hal ini adalah Strength (kekuatan atau potensi) dan Weakness (kelemahan atau kendala). Faktor eksternal terdiri dari Opportunity (peluang) dan Threat (ancaman). Analisis SWOT digunakan untuk memperoleh pandangan dasar mengenai Strategi yang diperlukan dalam mencapai suatu tujuan tertentu, dalam hal ini pengkajian tentang upaya-upaya apa saja yang dapat dijadikan solusi alternatif dalam pengelolaan dan pengembangan Pantai Nguyahan, Ngobaran,
Ngrenehan, Ngeden, dan Butuh di Kecamatan Saptosari.

\section{HASIL DAN PEMBAHASAN}

Kecamatan Saptosari merupakan salah satu kecamatan di Kabupaten Gunungkidul yang terdiri dari 7 desa, yakni Jetis, Monggol, Nglora, Kepek, Plajan, Kanigoro dan Krambilsawit. Secara geografis Kecamatan Saptosari terletak pada 8॰02'47" - 8० 05’36” LS dan 110'28'55"- 110'33'13” BT, dengan luas wilayah Kecamatan Saptosari $\pm 87,83 \mathrm{~km}^{2}$.

Berdasarkan materi teknis yang tertulis pada Rencana Tata Ruang Wilayah (RTRW) Kabupaten Gunungkidul Tahun 2010-2030, wilayah pesisir Kecamatan Saptosari meliputi 3 desa, yaitu Desa Krambilsawit $\left(14,79 \mathrm{~km}^{2}\right)$, Desa Kanigoro $\left(24,88 \mathrm{~km}^{2}\right)$ dan Desa Planjan $\left(12,48 \mathrm{~km}^{2}\right)$.



Gambar 1. Peta Administratif Wilayah Pesisir Kecamatan Saptosari

\section{Pantai Nguyahan}

Pantai Nguyahan terletak di Desa Kanigoro Kecamatan Saptosari. Pantai Nguyahan mempunyai daya tarik yang kuat. Salah satu daya tarik Pantai Nguyahan mempunyai pasir putih dan keindahan cliff yang menjadi salah satu daya tarik wisatawan. Selain itu, gelombang laut yang cukup aman menjadi pilihan beberapa wisatawan untuk berenang. Aksesibilitas menuju ke lokasi wisata yang baik dan berdekatan dengan pantai
Ngobaran menambah daya tarik Pantai Nguyahan. Sehingga Karakteristik pengunjungnya hampir sama dengan pengunjung pantai Ngobaran. Namun, beberapa masalah yang muncul di Pantai Nguyahan diantaranya infrastruktur yang kurang baik dan kurang tertata, wahana wisata yang belum ada membuat para wisatawan cepat bosan, dan masih terdapat sampah yang berserakan di beberapa spot wisata. 


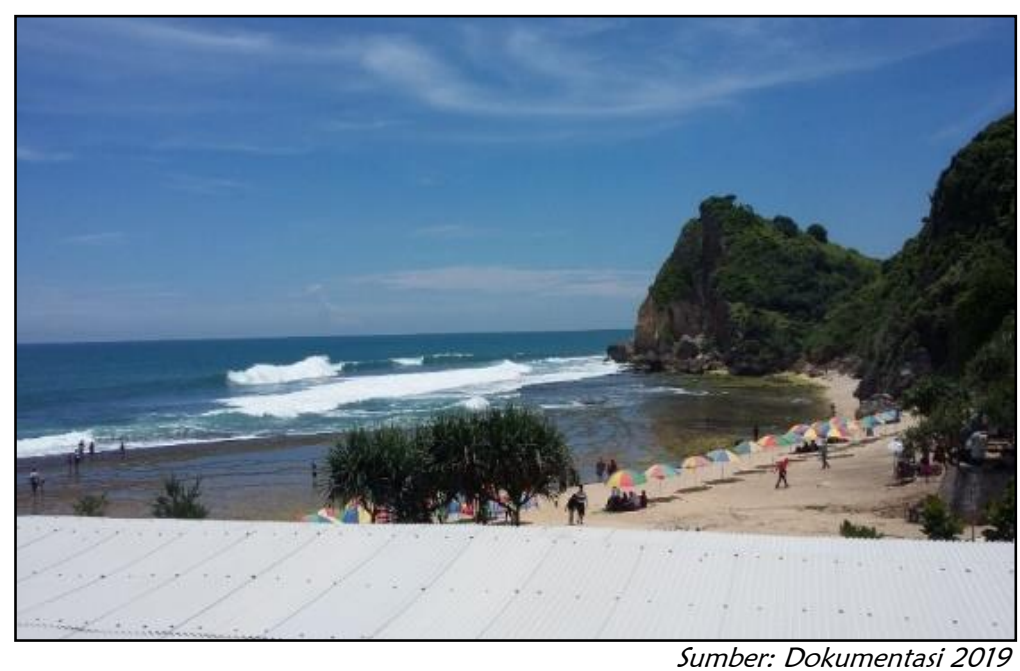

Gambar 2. Pantai Nguyahan

Potensi yang mampu menambah daya tarik dari wisata pantai di Nguyahan yakni terdapat pantai yang masih belum dikelola. Lokasi pantai ini berdekatan dengan pantai Nguyahan. Masyarakat setempat biasanya menyebutnya dengan pantai Pringjono. Aksesibilitas untuk menuju pantai Pringjono masih sulit, untuk itu perlu peran serta kelompok pengelola wisata dan peran pemerintah untuk memperbaiki aksesibilitas ke lokasi Pantai Pringjono

Penataan lokasi berdagang di Pantai Nguyahan sangat baik, namun kurang strategis. Hak milik bangunan di Pantai Nguyahan statusnya disewakan dengan biaya retribusi Rp. 200.000 per tahun. Banyaknya pengunjung yang datang pada lokasi wisata Pantai Nguyahan pada hari biasa 10-15 orang sedangkan pada hari libur 40-50 orang. Pengunjung yang datang berasal dari berbagai daerah Jogja, Semarang, Jakarta, dll. Harapan pedagang di Pantai Nguyahan, pemerintah lebih memperkenalkan lokasi wisata, memberikan modal kepada pedagang dan menghilangkan retribusi di lokasi wisata.

Pengembangan wisata pantai Nguyahan dengan menggabungkan pantai Pringjono sangat diperlukan agar mampu menambah daya tarik wisatawan. Pengembangan wisata pantai Nguyahan diharapkan mampu menjadi wisata andalan di Kecamatan Saptosari dan mampu memberi manfaat kepada masyarakat sekitar. Banyak peluang yang bisa dikembangkan untuk menambah daya tarik wisata pantai Nguyahan. Beberapa strategi pengembangan wisata pantai Nguyahan dapat dilihat pada tabel SWOT dalam Tabel 1.

\section{Pantai Ngobaran}

Pantai Ngobaran terletak di sebelah Pantai Nguyahan terletak di Desa Kanigoro Kecamatan Saptosari. Pantai Ngobaran memiliki ciri khas yang tidak dimiliki oleh pantai lain di Kecamatan Saptosari. Ciri khas pantai Ngobaran yakni adanya bangunan pure. Pure ini dibangun oleh sultan agung Yogyakarta. Adanya cliff menambah keindahan Pantai Nguyahan. Namun, beberapa masalah yang ada di pantai Nguyahan yakni parkir yang kurang tertata mengurangi keindahan pantai Nguyahan, tidak terdapat pagar/pembatas pada lokasi wisata yang berdekatan dengan tebing.

Pantai ngobaran sendiri terkenal dengan kuliner rumput laut dan landak laut. Jenis usaha yang terdapat pada pantai ngobaran yaitu kioskios yang menjual makanan ringan dan minuman, Rumah makan sederhana, Pedagang buah, Pedagang cilok, pedagang bakso, persewaan kamar mandi, jasa foto, dan jasa parkir. Pantai ini pengunjungnya lebih banyak daripada pantai-pantai lain yang diteliti, karena akses yang lebih mudah dan jalan yang sudah baik. Adapun pengunjung berasal dari berbagai daerah lokal maupun internasional. Objek wisata ini dikelola oleh masyarakat asing yang menanamkan modal serta masyarakat lokal sebagai pengusaha di sekitar pantai. Pengunjung merasa lebih tertarik akan keberadaan pantai ini karena sudah dibenahi dengan baik

Pantai Ngobaran tergolong pantai yang cukup ramai. Pantai Ngobaran di kelola oleh kelompok masyarakat Pokdarwis. Penduduk asli Desa Kanigoro di izinkan berjualan di lokasi wisata. Hak kepemilikan bangunan pedagang 
adalah milik pribadi. Pembayaran biaya retribusi di pantai ngobaran secara suka rela. Pada hari biasa pengunjung yang berbelanja sekitar 10-15 orang sedangkan pada hari libur 40-50 orang. Pengunjung yang datang di pantai ngobaran dari berbagai tempat yakni Jogja, Purwodadi, Jakarta, DIl. Harapan pedagang untuk melancarkan berjualan di lokasi wisata yakni perlu adanya perluasan lokasi berdagang. Pedagang tidak berharap pemerintah mengelola lokasi wisata karena sudah mempunyai kelompok masyarakat.

Strategi pengembangan pantai Ngobaran perlu direncanakan dengan matang. Beberapa pihak harus terlibat langsung dalam perencanaan pengembangan wisata Pantai Nguyahan seperti halnya kelompok pengelola pariwisata serta peran serta pemerintah daerah dalam memberikan dukungan atau bantuan untuk pengembagan wisata. Peran serta pihakpihak tersebut akan memberi kontribusi positif terhadap perkembangan pariwisata. Beberapa strategi yang bisa diterapkan dalam pengembangan Pantai Ngobaran bisa dilihat pada tabel SWOT dalam Tabel 1.

\section{Pantai Ngrenehan}

Pantai Ngrenehan terletak di Desa Kanigoro Kecamatan Saptosari kurang lebih 30 km di sebelah selatan Kota Wonosari. Suatu pantai berupa teluk yang di kelilingi hamparan perbukitan kapur dan memiliki panorama yang sangat memukau dengan deburan ombak menerpa pasir putih. Para wisatawan dapat menyaksikan aktivitas kegiatan nelayan dan menikmati ikan siap saji atau membawa ikan segar sebagai oleh-oleh.

Pantai ini awalnya merupakan kawasan pelelangan ikan, kemudian berkembang menjadi dua fungsi yaitu perikanan dan wisata. Motivasi pengunjung datang ke lokasi ini adalah untuk berbelanja dan wisata foto karena perahu nelayan yang terlihat indah di pantai yang jernih dan bukit karst yang unik. Tetapi sangat disayangkan oleh beberapa wisatawan mancanegara yang ditemui di lokasi mengemukakan bahwa ada sedikit perasaan terkejut karena foto-foto yang beredar di media sosial tidak semenarik kenyataan di lokasi. Banyak yang harus diperbaiki terutama dalam penataan lokasi pantai, lokasi pedagang dan sebaiknnya dilakukan atraksi budaya yang membedakannya dengan pantai lain di negara yang berkembang.



Sumber: Dokumentasi 2019

Gambar 3. Pantai Ngrenehan dan Pengunjung 
Fasilitas yang disediakan di kawasan pantai ini adalah tempat ibadah (Masjid), Tempat Pelelangan Ikan (TPI), warung makan disekitar pantai, kamar mandi umum dan tempat parkir. Oleh-oleh yang menarik di tempat ini adalah hasil tangkapan laut segar. Beberapa destinasi lain dari Pantai Ngrenehan adalah pemandangan dengan pasir putih dan tebing yang indah, menjadi daya tarik bagi wisatawan lokal maupun macanegara, perikanan merupakan salah satu produk unggulan. Namun, beberapa masalah yang terdapat di pantai ini yaitu kebersihan lingkungan wisata rendah, kondisi fasilitas (sarana \& prasarana) pariwisata yang kurang terawat dan kurang baik, PKL yang berjualan disembarang tempat, keterbatasan jenis atraksi (wahana) pariwisata yang dapat dijumpai.

Aktivitas pedagang Pantai Ngerenehan selalu aktif setiap hari. Dalam hal kepemilikan bangunan, warung milik para pedagang sedangkan hak atas tanah milik Sultan Ground. Berdasarkan hasil wawancara dengan para pedagang, banyaknya pengunjung yang berbelanja pada lokasi wisata pada hari biasa 10-15 orang sedangkan pada hari libur sekitar 50 orang atau lebih. Pengunjung berasal dari berbagai tempat yakni Jogja, Semarang, solo, sekitar pulau jawa, luar pulau jawa dan ada wisatawan mancanegara. Pedagang berharap pemerintah bekerjasama dengan kelompok masyarakat untuk mengelola lokasi wisata, pedagang tak berharap adanya swasta yang masuk di lokasi wisata, dan perlu adanya penataan lokasi berdagang agar lebih nyaman.

Berdasarkan potensi dan masalah di atas, maka peluang yang bisa dikembangkan yaitu Mengembangan wisata kuliner (lkan laut), menjalin kerjasama dengan kelompok pengelola pariwisata dan pemerintah daerah serta mengembangkan produk olahan ikan menarik pengunjung. Selain itu, permasalahan yang ada pada Pantai Ngrenehan bisa diselesaikan dengan membentuk tim kebersihan, melakukan perbaikan dan penataan infrastruktur serta penataan tempat parkir kapal agar semakin indah, membuat kebijakan untuk penataan PKL, serta mengembangkan wahana yang bisa dinikmati pariwisata.

\section{Pantai Ngeden}

Pantai Ngeden merupakan salah satu pantai yang terdapat di Desa Krambilsawit Kecamatan Saptosari. Pantai Ngeden mempunyai beberapa daya tarik untuk memikat wisatawan baik lokal atau mancanegara. Beberapa daya tarik atau kekuatan dari Pantai Ngeden yaitu pantai yang memiliki pasir putih dan cliff yang indah, serta lokasi pantai yang luas. Letak Pantai Ngeden berdekatan dengan lokasi wisata lain yang berpeluang untuk dijadikan satu kompleks wisata. Namun, beberapa masalah yang ada di Pantai Ngeden yaitu infrastruktur yang kurang baik dan kurang lengkap, fasilitas yang kurang lengkap, dan kebersihan kurang terjaga.

Pantai yang ini termasuk pantai yang baru dikembangkan sekitar dua tahun. Oleh karena itu ketersediaan sarana dan prasarana seperti kios-kios dan warung makan yang ada di pantai ini masih terbatas. Aktivitas berjualan masih terbatas pada hari-hari tertentu seperti hari libur atau sabtu, minggu. Sedangkan pada hari biasa yaitu Senin-Jumat hanya ada satu atau dua pedagang saja yang tetap berjualan.

Pengunjung dari wisata pantai ini masih terbatas dan biasanya merupakan pengunjung yang memiliki nyali tinggi dan termotivasi untuk wisata minat khusus. Jalur jalan yang terjal, berkelok-kelok dan masih banyak batubatu besar di jalan menjadikan jalur menuju objek wisata menantang. Adapun yang menjadi pengunjung pada Pantai Ngedan dan Pantai Butuh adalah masyarakat setempat, pelajar dan mahasiswa dari Yogyakarta, Solo Cirebon dan lain-lain, pegawai negeri sipil, wiraswasta, ibu rumah tangga, calon investor dan wisatawan mancanegara. Adapun motivasi dari pengunjung adalah untuk berfoto, melihat keindahan laut, pasir, karst, berkemah, wisata minat khusus. Jika dibandingkan antara Pantai Ngedan dan Pantai Butuh, yang lebih berkembang pengelolaan pariwisatanya adalah Pantai Ngedan sehingga pengunjung yang paling banyak adalah ke Pantai Ngedan.

Pengelola objek wiasata Pantai Ngedan menyediakan fasilitas warung-warung untuk berjualan dengan sistem sewa perbulan. Seperti penuturan bapak Rukijon salah satu pedagang di Pantai Ngedan mengatakan bahwa "Ratarata warung di Pantai Ngedan bukan milik pribadi namun bersifat penyewaan perbulan dengan tarif suka rela dari pedagang". Jumlah pengunjung yang datang pada hari biasa 5-10 orang sedangkan pada hari libur atau sabtu/minggu sekitar 10-30 orang, Yang berasal dari Jogja, Semarang, Solo, dll. Namun para pedagang berharap adanya perhatian dari pengelola atau pemerintah untuk memperbaiki akses menuju ke Pantai Ngedan, dan mereka juga berharap adanya perbaikan warungwarung agar dapat menarik wisatawan serta bantuan modal. 


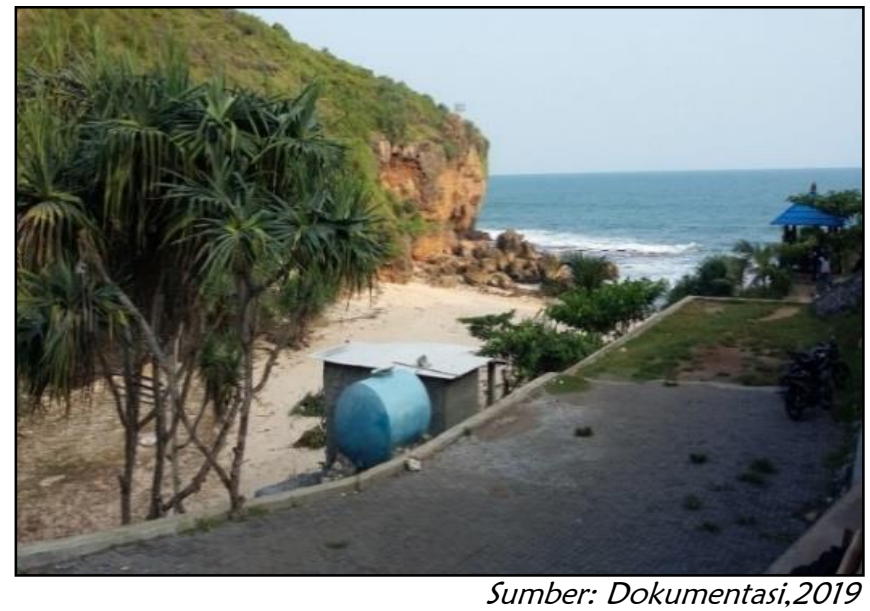

Gambar 4. Pantai Ngedan

Ada beberapa temuan yang terkumpul berdasarkan wawancara dengan pengunjung. 1) Pengunjung pariwisata yang berasal dari luar negeri biasanya menginap di sebuah villa di Pantai Ngedan yang telah dimiliki oleh orang Belanda. Keberadaan villa tersebut menambah kenyamanan wisatawan mancanegara untuk berwisata di pantai tersebut. 2) Pengunjung yang intens dari masyarakat ke objek wisata biasanya karena keinginan untuk melakukan survey lokasi, melihat peluang pengembangan wisata yang pengolahannya dipegang sepenuhnya untuk masyarakat sekitar bukan orang luar. Hal ini juga didorong dengan terbentuknya organisasi masyarakat pemerhati Objek Wisata

Beberapa peluang yang berpotensi kuat untuk dikembangkan di Pantai Ngeden yakni pengembangan wisata minat khusus seperti camping dan tracking. Pengembangan wisata pantai dengan minat khusus akan menambah daya tarik pada wisata Pantai Ngeden. Pengembangan wisata Pantai Ngeden akan memberi pengaruh terhadap aktivitas ekonomi masyarakat yang semakin dinamis dan berkembang. Strategi pengembangan wisata Pantai Ngeden bisa dilihat pada tabel matriks dalam Tabel 1.

\section{Pantai Butuh}

Lokasi pantai Butuh terletak di Desa Krambilsawit Kecamatan Saptosari Kabupaten Gunungkidul Daerah Istimewa Yogyakarta. Pantai Butuh berdekatan dengan Pantai Ngeden dan Nglimun. Pantai Butuh memiliki beberapa keunggulan diantaranya pantai pasir putih, yang memiliki landscape yang indah, lokasi wisata searah dengan objek wisata lain, mempunyai tebing cliff yang indah. Beberapa keunggulan yang dimiliki Pantai Butuh menjadi daya tarik para pengunjung wisata. Namun, beberapa masalah yang ada di Pantai Butuh menjadi faktor penghambat perkembangan wisata ini. Masalah-masalah yang ada diantaranya infrastruktur jalan yang kurang baik, hanya ada satu warung, sulit air, sarana dan prasarana kurang, dan belum ada komunitas dari masyarakat setempat.

Pantai Butuh mulai dikenal sekitar setahun lalu. Pantai butuh hanya terdapat satu kios milik penjaga pantai. Dengan status tempat milik sendiri, dan tidak ada biaya retribusi selama satu tahun terakhir. Hasil wawancara yang di lakukan dengan pedagang Pantai Butuh yaitu bapak Surminto menuturkan bahwa Pengunjung yang datang pada lokasi wisata Pantai Butuh di hari biasa sekitar 5-10 orang, sedangkan pada hari libur 30-35 orang. Wisatawan yang datang ke Pantai Butuh dari berbagai daerah, jogja, Purwodadi, Semarang, dll. Akses menuju pantai butuh masih jauh dari kata layak. Hal tersebut mengakibatkan wisatawan yang datang di pantai butuh belum terlalu banyak. Harapan pedagang di Pantai Butuh "adanya pembangunan lokasi wisata yang memadai dan Pemerintah dapat membantu mempromosikan lokasi wisata Pantai Butuh.

Potensi atau peluang yang bisa dikembangkan di Pantai Butuh yaitu mengembangkan wisata camping, menyediakan alat penyewaan camping, mengadakan kalender event yang rutin dilaksanakan untuk menarik pengunjung, dan mengembangkan wisata tracking. Pengembangan wisata pantai Butuh harus didukung oleh beberapa pihakpihak tekait seperti pemerintah daerah, pemerintah desa serta masyarakat/kelompok pengelolah pariwisata. Perkembangan pariwisata ini diharapkan mampu berpengaruh positif terhadap kesejahteraan masyarakat. 
Tabel 1. Strategi Prioritas Pengembangan Wisata 5 Pantai di Kecamatan Saptosari dari hasil Analisis tabel SWOT

\begin{tabular}{|c|c|c|c|c|c|}
\hline No & Strategi Prioritas & Kegiatan & Lokasi & Instansi Pelaksana & Sumber Pendanaan \\
\hline 1 & Mengembangkan wahana wisata dari segala umur & $\begin{array}{l}\text { Pembangunan infrastruktur dan } \\
\text { penyediaan permainan }\end{array}$ & Nguyahan & $\begin{array}{l}\text { Dinas pariwisata, kelompok } \\
\text { pariwisata }\end{array}$ & APBD \\
\hline 2 & $\begin{array}{l}\text { Mengadakan event yang menarik secara rutin (kalender } \\
\text { event regional/nasional/international) }\end{array}$ & Event kebudayaan, perlombaan sepeda & $\begin{array}{l}\text { Nguyahan, Ngobaran, } \\
\text { Ngrenehan, Butuh, Ngedan }\end{array}$ & $\begin{array}{l}\text { Dinas pariwisata, kelompok } \\
\text { pariwisata }\end{array}$ & APBD/ Dana Desa \\
\hline 3 & Membangun jaringan telekomunikasi & $\begin{array}{l}\text { Pembangunan infrastruktur } \\
\text { telekomunikasi }\end{array}$ & $\begin{array}{l}\text { Nguyahan, Ngobaran, } \\
\text { Ngrenehan, Butuh, Ngedan }\end{array}$ & $\begin{array}{l}\text { Pemerintah kabupaten/Dinas } \\
\text { pariwisata }\end{array}$ & APBD \\
\hline 4 & $\begin{array}{l}\text { Penetapan sebagai kawasan wisata andalan di } \\
\text { kecamatan Saptosari }\end{array}$ & Pembuatan kebijakan & Nguyahan, Ngobaran & $\begin{array}{l}\text { Pemerintah kabupaten/Dinas } \\
\text { pariwisata }\end{array}$ & APBD \\
\hline 5 & $\begin{array}{l}\text { Membuka kawasan wisata pringjono untuk memperluas } \\
\text { destinasi wisata di Nguyahan }\end{array}$ & $\begin{array}{l}\text { Membuka akses jalan ke pantai } \\
\text { Pringjono, pengembangan infrastruktur }\end{array}$ & Nguyahan & kelompok /pengelola pariwisata & Dana Desa \\
\hline 6 & $\begin{array}{l}\text { Meningkatkan diversifikasi produk yang khas untuk } \\
\text { cinderamata wisatawan }\end{array}$ & $\begin{array}{c}\text { Pemberdayaan masyarakat dengan } \\
\text { membentuk kelompok-kelompok } \\
\text { pembuat cinderamata }\end{array}$ & Nguyahan, Ngobaran & kelompok /pengelola pariwisata & Dana Desa \\
\hline 7 & $\begin{array}{l}\text { Melakukan komunikasi dengan kedua kelompok } \\
\text { pengelola wisata dengan didampingi oleh tokoh } \\
\text { masyarakat atau pemerintah daerah }\end{array}$ & Musyawarah atau diskusi & Nguyahan, Ngobaran & $\begin{array}{l}\text { Pemerintah kabupaten/Dinas } \\
\text { Pariwisata, pemerintah desa, }\end{array}$ & Dana Desa \\
\hline 8 & $\begin{array}{l}\text { Membentuk petugas kebersihan agar tercipata pantai } \\
\text { yang bersi }\end{array}$ & $\begin{array}{l}\text { Musyawarah atau diskusi untuk } \\
\text { menentukan penanggung jawab } \\
\text { kebersihan }\end{array}$ & $\begin{array}{l}\text { Nguyahan, Ngobaran, } \\
\text { Ngrenehan, Butuh, Ngedan }\end{array}$ & Kelompok pariwisata & Dana Desa \\
\hline 10 & $\begin{array}{l}\text { Menyediakan lahan parkir kendaraan khusus agar } \\
\text { terlihat rapi }\end{array}$ & $\begin{array}{l}\text { Membuka dan memperluas lahan parker } \\
\text { agar tertata secara rapi }\end{array}$ & Ngobaran & Kelompok pariwisata & Dana Desa \\
\hline 11 & Melakukan pentaan infrastruktur agar lebih indah & Penataan dan pembangunan ifrastruktur & Ngobaran & $\begin{array}{l}\text { Dinas pariwisata dan kelompok } \\
\text { pariwisata }\end{array}$ & APBD \\
\hline 12 & $\begin{array}{l}\text { Mengembangan wisata kuliner (Ikan laut) dan } \\
\text { mengembangkan produk olahan ikan yang menarik }\end{array}$ & $\begin{array}{l}\text { Pembentukan kelompok pengelola aneka } \\
\text { olahan ikan }\end{array}$ & Ngrenehan & kelompok pariwisata & Dana Desa \\
\hline 13 & $\begin{array}{l}\text { Mendesain pantai ngeden sebagai wisata andalan untuk } \\
\text { minat khusus seperti camping dan tracking }\end{array}$ & $\begin{array}{l}\text { Membentuk kelompok pariwisata } \\
\text { dengan pembagian tanggung jawab } \\
\text { secara jelas }\end{array}$ & Ngedan dan Butuh & $\begin{array}{l}\text { Dinas pariwisata dan kelompok } \\
\text { pariwisata }\end{array}$ & Dana Desa \\
\hline 14 & Menyediakan alat penyewaan camping & Membentuk kelompok pariwisata & Ngedan dan Butuh & $\begin{array}{l}\text { Dinas pariwisata dan kelompok } \\
\text { pariwisata }\end{array}$ & Dana Desa \\
\hline 15 & $\begin{array}{l}\text { Memperbaiki infrastruktur seperti jalan dan fasilitas } \\
\text { umum }\end{array}$ & $\begin{array}{l}\text { Menjalin kerjasama dengan pemerintah } \\
\text { daerah }\end{array}$ & Ngedan dan Butuh & $\begin{array}{l}\text { Dinas pariwisata dan kelompok } \\
\text { pariwisata }\end{array}$ & APBD \\
\hline
\end{tabular}




\section{KESIMPULAN}

1. Wisata Pantai Ngedan dan Pantai Butuh yang berada di Desa Kerambilsawit masih belum mendapatkan pengelolaam secara serius. Kondisi infrastruktur di kedua pantai masih belum tersedia secara lengkap. Selain itu, komunitas pengelola wisata belum tebentuk. Untuk itu, perlu adanya kerjasama antara pemerintah daerah dan masyarakat desa untuk memperbaiki infrastruktur seperti jalan dan fasilitas umum lainnya. Pembentukan komunitas pengelola wisata mempunyai peran penting dalam mengelola wisata Pantai Ngedan dan Pantai Butuh. Dengan adanya komunitas pengelola pariwisata maka program-program pengembangan wisata yang direncanakan dapat dilaksanakan dengan mudah. Pantai Ngedan dan Pantai Butuh berpotensi dikembangkan sebagai wisata andalan untuk minat khusus seperti camping dan tracking. Pengembangan wisata minat khusus akan memberi kontribusi positif terhadap pendapatan masyarakat karena sektor-sektor perekenomian lain ikut bergerak.

2. Wisata Pantai Nguyahan, Pantai Ngobaran, dan pantai Ngrenehan yang terdapat di Desa Kanigoro memiliki keindahan alam yang luar biasa. Pantai Nguyahan dan Pantai Ngobaran ini berpotensi untuk dikembangkan wisata unggulan di Kecamatan Saptosari. Strategi prioritas pengembangan Pantai Nguyahan dengan mengembangkan wahana wisata dari segala umur serta membuka pantai Pringjono sebagai destinasi wisata terbaru yang terintegrasi dengan kawasan wisata Nguyahan dan Ngobaran. Selain itu, strategi lain yang bisa dilakukan yakni mengadakan event yang menarik secara rutin (kalender event regional/ nasional/ international) dengan menjalin kerjasama dengan kelompok pengelola pariwisata. Sedangkan Pantai Ngrenehan yang memiliki dua kegitan yakni pariwisata dan perikanan harus dilakukan penataan infrastruktu agar semakin indah. Pengembangan pariwisata ini harus didukung dengan pembangunan infrastruktur dan SDM agar rencana yang sudah dituliskan dapat terlaksana dengan baik.

\section{DAFTAR PUSTAKA}

Hildebrandt, T. H. (1966). Linear continuous functionals on the space (BV) with weak topologies. Proc. Amer. Math. Soc., 17, 658 - 664.

Lewis, Catherine C. 2002. Lesson Study: A Handbook of Teacher-Led Instructional Change. Philadelphia, PA: Research for Better School, Inc.

Pendit, N. S. 1990. Ilmu Pariwisata. Jakarta: Pradnya Paramita.

Simond, J. O. 1978. Earthscape. London.

Sujali. 1989. Geografi Pariwisata dan Kepariwisataan. Yogyakarta: Fakultas Geografi Universitas Gadjah Mada.

Wardiyanta. 2006. Metode Penelitian Pariwisata. CV. Andi Offset, Yogyakarta.

Yoety, 1983. Komersialisasi Seni Budaya dalam Pariwisata. Bandung: Angkasa Offset.

Yulianda, F. 2007. Ekowisata Bahari sebagai Alternatif Pemanfaatan Sumberdaya Pesisir Berbasis Konservasi. Disampaikan pada Seminar Sains 21 Februari 2007. Bogor: Departemen MSP. FPIK. IPB

Sevilla, Consuelo et al, Al. 1993. Pengantar Metode Penelitian. Jakarta: Universitas Indonesia Press. 
